\title{
Anemia infecciosa eqüina: prevalência em eqüídeos de serviço em Minas Gerais
}

\author{
[Equine infectious anemia: prevalence in working equids of livestock herds, in Minas Gerais, Brazil]

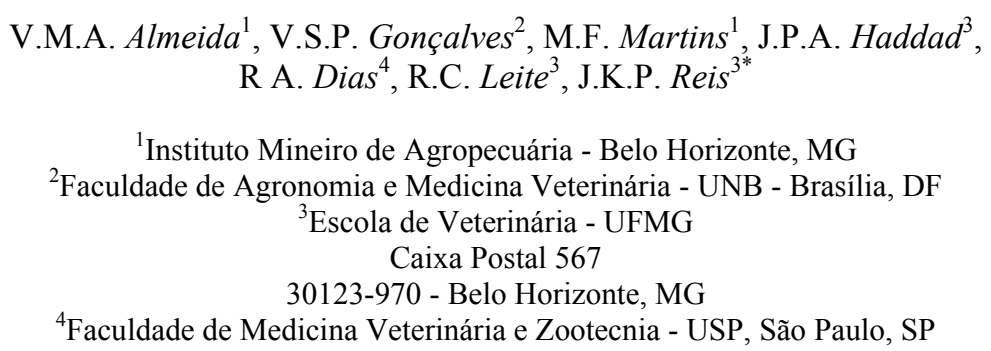

\section{RESUMO}

Estimaram-se, no estado de Minas Gerais, a prevalência e a distribuição espacial da anemia infecciosa eqüina (AIE) em propriedades com eqüídeos de serviço. As amostras de sangue, de 6540 eqüídeos de 1940 rebanhos foram coletadas no período de setembro de 2003 a março de 2004, nos 853 municípios do estado. Utilizaram-se dois testes de laboratório em seqüência: ELISA, usando-se antígeno recombinante gp90, e imunodifusão em gel de ágar (IDGA). As prevalências foram de 5,3\% [IC=4,3 a 6,3\%] para rebanhos e de 3,1\% [IC=2,2 a 3,9\%] para animais. $\mathrm{O}$ estado de Minas Gerais foi considerado área endêmica para AIE. As mais altas prevalências para rebanhos e para animais foram encontradas na região Norte/Noroeste, seguida pela região Vale do Mucuri/Jequitinhonha.

Palavras-chave: eqüídeos, anemia infecciosa, ELISA, IDGA

\begin{abstract}
The prevalence and spatial distribution of equine infectious anemia (EIA) were estimated in livestock herds where equids were used as draft power and for transportation in the State of Minas Gerais, Brazil. Serum samples were collected from September/2003 to March/2004 in 853 municipalities of the state. The sample comprised 6,540 equids from 1,940 herds. Two laboratorial tests were performed in sequence: ELISA using a recombinant gp90 protein, following by the AGID. The prevalence in the herds was estimated in $5.3 \%$ [CI $=4.3$ to $6.3 \%]$, and $3.1 \%[C I=2.2$ to $3.9 \%]$ of the animals tested were positive. Minas Gerais was considered an endemic region for EIA. The highest prevalence for herds and animals was found in North/Northwest region (strata) followed by Vale do Mucuri/Jequitinhonha region.
\end{abstract}

Keywords: equid, infectious anemia, ELISA, AGID

\section{INTRODUÇÃO}

O Brasil ocupa a terceira posição mundial em relação ao número de eqüídeos após o México e a China (Ganaderia..., 2002). Segundo o IBGE (Banco... 2001), o rebanho eqüídeo brasileiro é

Recebido em 13 de julho de 2005

Aceito em 3 de janeiro de 2006

*Autor para correspondência (corresponding author)

E-mail: jenner@coltec.ufmg.br

Apoio: FAPEMIG de 8.385.736 animais, sendo que $13 \%$ desse efetivo, ou seja, 1.128.754, encontra-se em território mineiro, distribuídos em 12 mesorregiões.

O mercado para o eqüídeo nacional e, principalmente, o mineiro está em visível expansão, constituindo uma importante cadeia do agronegócio, com estreita relação com os setores ligados ao lazer, à cultura, ao turismo entre outros. 
A anemia infecciosa eqüina (AIE) é uma enfermidade cosmopolita, causada por um vírus do gênero Lentivirus da família Retroviridae, e acomete os eqüídeos (Issel e Coggins, 1979; Clabough, 1990; Cook et al., 2001).

A AIE é, hoje, um grande obstáculo para o desenvolvimento da eqüideocultura, por ser uma doença transmissível e incurável, acarretando prejuízos aos proprietários que necessitam do trabalho desses animais e aos criadores interessados na melhoria das raças, além de impedir o acesso ao mercado internacional.

O diagnóstico laboratorial é de fundamental importância para detecção dos portadores da doença, que, de acordo com a legislação (Brasil... 2004) devem ser sacrificados, promovendo o saneamento dos rebanhos.

Em 1970, o teste de imunodifusão em gel de ágar (IDGA) foi descrito constituindo um marco no diagnóstico de AIE, por ser de fácil execução, relativamente sensível e específico (Coggins e Norcross, 1970). Foi o primeiro teste disponível comercialmente e o único teste prescrito, oficialmente, para trânsito pela Organização Mundial de Sanidade Animal, apesar de apresentar algumas limitações, dentre elas, a incapacidade de detectar anticorpos para o vírus da AIE (VAIE) nos estádios iniciais da doença.

Testes mais sensíveis e capazes de detectar anticorpos para o VAIE, mais precocemente em relação ao IDGA e baseados na técnica de ELISA, têm sido descritos (Shane et al., 1984; Shen et al., 1984; Sugiura et al., 1986; Reis et al., 1994; Reis, 1997). Os testes de IDGA e ELISA baseiam-se, primariamente, na detecção de anticorpos para a proteína do core viral denominada p26, porém já foi demonstrado que os anticorpos específicos para a glicoproteína gp90 da superfície viral são $10^{2}$ a $10^{3}$ vezes mais abundantes do que anticorpos específicos para p26 (Montelaro et al., 1984), sendo também os primeiros a serem detectados no sangue.

Um ELISA, utilizando gp90 recombinante, foi desenvolvido por Reis (1997), e demonstrou ser mais eficiente do que o ELISA com antígeno p26, pois detectou anticorpos para o VAIE mais precocemente em animais infectados, apresentou boa correlação com os resultados do teste de
IDGA e foi recomendado como teste de triagem em levantamentos sorológicos (Martins, 2004).

As estatísticas oficiais apresentam um perfil da situação epidemiológica da AIE, porém não informam, com exatidão, a taxa de prevalência da enfermidade em Minas Gerais e nos demais estados do país, uma vez que se referem, exclusivamente, aos exames laboratoriais realizados para o trânsito interestadual e/ou participação em eventos agropecuários controlados pelos serviços oficiais de defesa sanitária animal. A maior parte do efetivo eqüídeo testado pertence a rebanhos de alto valor zootécnico em que a doença está controlada e, muitas vezes, o mesmo animal é testado mais de uma vez durante um curto período. Não há, em Minas Gerais, um estudo de prevalência da AIE a partir de dados primários, para que se possa estabelecer uma política sanitária adequada para o controle e futura erradicação da enfermidade.

O objetivo desta pesquisa foi a realização de um inquérito soroepidemiológico da AIE a partir de dados primários coletados em todo o estado de Minas Gerais, visando estimar a prevalência e a distribuição espacial da AIE, de propriedades com eqüídeos de serviço, e a prevalência de eqüídeos de serviço positivos para a referida doença.

\section{MATERIAL E MÉTODOS}

A área estudada foi o estado de Minas Gerais, que se localiza na região Sudeste do Brasil, e abrange uma superfície de $588.384,6 \mathrm{~km}^{2}$. A pesquisa compreendeu propriedades de eqüídeos de serviço, com baixo valor zootécnico e, em sua maioria, sem raça definida. Considerando a diversidade e as dimensões de Minas Gerais, o estado foi dividido em sete estratos que contemplaram as 12 mesorregiões definidas pelo IBGE (Tab. 1). Estabeleceu-se que cada estrato deveria conter, pelo menos, $10 \%$ da população de eqüídeos do estado, a fím de evitar a fragmentação excessiva da amostragem, assegurando, assim, que o tamanho da amostra fosse compatível com a capacidade operacional e laboratorial. Houve agrupamento de mesorregiões nos estratos 1, 2, 4 e 7, levando em consideração a contigüidade geográfica e a densidade eqüídea. 
O tamanho da amostra de rebanhos por estrato foi determinado de acordo com Noordhuizen et al. (1997), sendo condizente com a capacidade operacional do Instituto Mineiro de Agropecuária (IMA), utilizando-se a fórmula para amostras simples aleatórias, segundo Thrusfield (1995):

$$
\mathrm{n}=\frac{\mathrm{Z}_{\alpha / 2}^{2} \cdot \mathrm{P}(1-\mathrm{P})}{\mathrm{d}^{2}}
$$

Os parâmetros da amostragem foram definidos da seguinte forma:

população eqüídea em estudo $=58.000$ rebanhos (maior número de propriedades rurais cadastradas no IMA, em um só estrato amostral, cuja atividade principal era a criação de bovinos); valor da distribuição normal para o grau de confiança de $95 \%\left(\mathrm{Z}_{\alpha / 2}\right)=1,96$; prevalência esperada $(\mathrm{P})=15 \%$; erro absoluto (d) $=5 \%$.
Com esses parâmetros, o número mínimo de propriedades a serem amostradas seria de 196. Em todos os estratos, amostrou-se um número maior de propriedades, visando melhorar a precisão da estimativa final e minimizar o efeito de perdas amostrais. Para cada um dos estratos, utilizou-se uma lista de produtores rurais ordenados por municípios. Procedeu-se a uma amostragem aleatória sistemática, o que permitiu que municípios com um maior número de propriedades apresentassem, proporcionalmente, um peso maior. Todos os 853 municípios do estado foram representados tendo, pelo menos, uma propriedade contemplada.

Foram amostradas, aleatoriamente, 1.940 propriedades, de um total de 298.916 estabelecimentos cadastrados pelo IMA, tendo como atividade principal a criação de bovinos, conforme dados apresentados na Tab. 1.

Tabela 1. Total de propriedades existentes e amostradas por estrato, em Minas Gerais, no período de setembro de 2003 a março de 2004

\begin{tabular}{lcc}
\hline Mesorregiões (estratos) & $\begin{array}{c}\text { Propriedades } \\
\text { existentes }\end{array}$ & $\begin{array}{c}\text { Propriedades } \\
\text { amostradas }\end{array}$ \\
\hline Norte/Noroeste de Minas (1) & 51.858 & 308 \\
Vale do Mucuri/Jequitinhonha (2) & 22.109 & 287 \\
Vale do Rio Doce (3) & 24.818 & 252 \\
Central Mineira/Oeste de Minas/Metrop. Belo Horizonte (4) & 57.796 & 293 \\
Sul/Sudoeste de Minas (5) & 54.522 & 278 \\
Triângulo Mineiro/Alto Paranaíba (6) & 39.822 & 232 \\
Campo das Vertentes/ Zona da Mata (7) & 47.991 & 290 \\
Total & 298.916 & 1.940 \\
\hline
\end{tabular}

Uma vez definido o número de unidades primárias de amostragem por estrato, definiu-se o número de unidades secundárias de amostragem, ou seja, o número de eqüídeos, a partir de seis meses de idade, que foram testados para AIE, com o objetivo de classificar as propriedades como positivas ou negativas. Para essa finalidade, foi necessário simular valores de sensibilidade e especificidade de rebanho.

O protocolo de testes foi composto do ELISA rgp90 (Reis, 1997) e do teste de IDGA $^{1}$ (Coggins e Norcross, 1970) utilizados em seqüência. Os soros positivos e os indeterminados ao ELISA foram testados pelo IDGA. No ELISA, os soros com leitura de densidade ótica $(\mathrm{DO}) \geq 0,220$ a

${ }^{1}$ Laboratório Vallée (kit).
0,263 foram considerados indeterminados, e os soros com DO $\geq 0,264$ foram considerados positivos (Martins, 2004).

A sensibilidade e a especificidade combinada dos testes empregados, em seqüência, foram calculadas a partir de estimativas individuais, ou seja, de sensibilidade de $98,8 \%$ e especificidade de $100 \%$ para o IDGA (Coggins et al., 1972; Issel, 2005 2 ) e de sensibilidade de $97,8 \%$ e de especificidade de $96,2 \%$ para o ELISA rgp90 (Martins, 2004). Assim, a sensibilidade do processo de diagnóstico, em série, foi de $96,6 \%$ (sensibilidade do teste $1 \times$ sensibilidade do teste

\footnotetext{
2 ISSEL, C. J. Comunicação pessoal. 2005. (Gluck Equine Research Center, Department of Veterinary Science, University of Kentucky, Lexington, KY; issel@uky.edu).
} 
2) e a especificidade em série, $100 \%$ [1 - (1 especificidade do teste 1$) \times(1$ - especificidade do teste 2) ].

Como os animais foram testados individualmente para determinar o estado do rebanho, $\mathrm{o}$ desempenho do método de diagnóstico (sensibilidade e especificidade) foi avaliado de forma agregada (Martin et al., 1992; Jordan, 1996; Noordhuizen et al., 1997).

Conhecendo a sensibilidade de rebanho (SenR), a especificidade de rebanho (EspR) e a prevalência aparente $(\mathrm{Pa})$ pode-se estimar a prevalência real (Pr) de rebanhos infectados e os valores preditivos positivo (VPP) e negativo (VPN) do diagnóstico. A prevalência real foi estimada pela fórmula: $\mathrm{Pr}=(\mathrm{Pa}+\mathrm{EspR}-$ 1)/(SensR + EspR - 1). Quando a prevalência é baixa, o valor preditivo positivo é muito baixo, a menos que a especificidade de rebanho seja próxima de 100\% (Martin et al., 1992). Assim, para evitar que o estudo produzisse um alto número de resultados falso-positivos, superestimando a prevalência aparente, o cálculo da amostra de animais foi feito de forma a ser obtida uma alta especificidade de rebanho, mantendo uma sensibilidade de rebanho de, pelo menos, $95 \%$.

A sensibilidade e a especificidade de rebanho dependem de: sensibilidade e especificidade do teste, de forma individual; número de animais testados e tamanho do rebanho; e número mínimo de animais positivos para classificar o rebanho como infectado (ponto de corte).

Utilizando-se o programa Herdacc (Herdacc..., 2003) foram simulados vários tamanhos de amostra, optando-se por um número fixo de 10 animais por rebanho, ou a sua totalidade, quando o mesmo fosse composto por um número menor que dez animais. Caso houvesse mais de uma espécie de eqüídeos, todas deveriam participar da amostra. A propriedade foi considerada positiva quando, ao menos, um animal positivo ao IDGA foi detectado, ou seja, o ponto de corte de animais sororreagentes foi igual a um (Donald e Gardner, 1994). Em razão da maior parte dos proprietários possuírem poucos eqüídeos de serviço - a população alvo deste estudo considerou-se que pelo menos um em cada quatro animais estaria infectado, nas propriedades onde a AIE estivesse presente.
Assim, na simulação utilizou-se o valor de $25 \%$ para a prevalência dentro do rebanho (Tab. 2).

Tabela 2. Simulação de valores de especificidade e sensibilidade de rebanho, para uma amostra de 10 animais, com diferentes tamanhos de rebanho e ponto de corte igual a um, segundo cálculos realizados com assistência do programa Herdacc $\AA$

\begin{tabular}{ccc}
\hline $\begin{array}{c}\text { Total de eqüídeos } \\
\text { no rebanho }\end{array}$ & $\begin{array}{c}\text { Especificidade } \\
\text { de rebanho }\end{array}$ & $\begin{array}{c}\text { Sensibilidade de } \\
\text { rebanho } \\
\text { Prevalência=25\% }\end{array}$ \\
\hline 5 & $100 \%$ & $100 \%$ \\
10 & $100 \%$ & $100 \%$ \\
15 & $100 \%$ & $99,6 \%$ \\
20 & $100 \%$ & $98,4 \%$ \\
30 & $100 \%$ & $96,2 \%$ \\
50 & $100 \%$ & $95,4 \%$ \\
\hline
\end{tabular}

A escolha dos animais, em cada propriedade, foi feita por amostragem aleatória. Foi amostrado, em Minas Gerais, um total de 6.540 animais distribuídos nos sete estratos (Tab. 3).

Tabela 3. Número (n) de eqüídeos de serviço amostrados por estrato em Minas Gerais

\begin{tabular}{lc}
\hline Mesorregiões (estratos) & Eqüídeos (n) \\
\hline 1. Norte/Noroeste de Minas & 1.077 \\
2. Vale do Mucuri/Jequitinhonha & 1.436 \\
3. Vale do Rio Doce & 917 \\
4. Central Mineira/Oeste de & 914 \\
$\quad$ Minas/Metrop. Belo Horizonte & \\
5. Sul/Sudoeste de Minas & 786 \\
6. Triângulo Mineiro/Alto Paranaíba & 706 \\
7. Campo das Vertentes/Zona da & 704 \\
Mata & \\
Total & 6.540 \\
\hline
\end{tabular}

As estimativas de prevalências e os intervalos de confiança (IC) foram obtidos com o auxílio do programa Epiinfo (Epiinfo..., 2004) usando o módulo Csample.

Considerando-se que a amostra de unidades primárias em cada estrato foi sistemática aleatória (Cochran, 1977), a prevalência aparente de focos de AIE foi estimada utilizando-se como parâmetros, o status da propriedade (foco ou livre da AIE), o estrato a que pertencia e o peso estatístico de cada propriedade no estrato, calculado pela razão entre o número de propriedades existentes e o número de propriedades amostradas em cada estrato (Dean, 1994). 
A prevalência aparente de animais soropositivos, com idade mínima igual ou superior a seis meses, foi estimada para os estratos e para o estado. Como, nesse caso, a escolha de unidades secundárias de amostragem foi feita por amostragem de grupos, os parâmetros utilizados nessa estimativa foram o status do animal (positivo ou negativo), o estrato regional ao qual pertencia a propriedade da qual foi retirada cada amostra, a identificação da propriedade no estudo e o peso estatístico de cada animal amostrado, cujo cálculo baseou-se na fórmula (Dean, 1994):

$$
\text { Peso }=\frac{\text { Eqüídeos existentes no estrato }}{\text { Eqüídeos amostrados no estrado }} \times \frac{\text { Animais existentes na propriedade }}{\text { Animais amostrados na propriedade }}
$$

\section{RESULTADOS E DISCUSSÃO}

Os resultados, apresentados na Tab. 4, confirmaram que a AIE é uma enfermidade endêmica em Minas Gerais, uma vez que, em todos os estratos foram detectados focos da doença. As maiores porcentagens de rebanhos de serviço positivos foram encontradas nos estratos 1 (Norte/Noroeste de Minas) com 14,9\% e 2 (Vale do Mucuri/Jequitinhonha) com 12,5\%, sendo essas as áreas de prevalência mais alta. No estrato 4 (Central Mineira/Oeste de Minas/Metropolitana de Belo Horizonte), encontrou-se a menor prevalência de rebanho do estado. Assim, Minas Gerais apresentou duas áreas de prevalência de rebanho distintas, sendo uma de prevalência alta, composta pelos estratos 1 e 2 ao norte, e outra, composta pelos demais estratos ao sul da primeira, com prevalência significativamente mais baixa.

A Pa geral de rebanhos de serviço e seus limites de IC (95\%) foram estimados em 5,3\% e 4,3 a $6,3 \%$, respectivamente. A estimativa de sensibilidade e especificidade de rebanho, para um total de até cinco animais por propriedade, seria de $100 \%$. Assim, a prevalência aparente foi considerada uma excelente aproximação do valor da prevalência real, uma vez que mais de $90 \%$ dos rebanhos amostrados tinham, em média, 4,4 animais.

Tabela 4. Prevalência de focos de AIE (rebanhos de serviço, positivos ao IDGA), por estrato, em Minas Gerais

\begin{tabular}{|c|c|c|c|c|}
\hline \multirow{2}{*}{ Estrato } & \multicolumn{2}{|c|}{ Propriedades } & \multirow{2}{*}{$\begin{array}{c}\text { Prevalência } \\
(\%) \\
\end{array}$} & \multirow{2}{*}{ 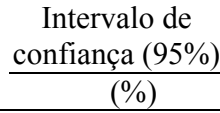 } \\
\hline & Amostradas & Positivas & & \\
\hline 1-Norte/Noroeste de Minas & 308 & 46 & 14,9 & {$[11,1$ a 19,4$]$} \\
\hline 2-Vale do Mucuri/Jequitinhonha & 287 & 36 & 12,5 & {$[8,9$ a 16,9$]$} \\
\hline 3-Vale do Rio Doce & 252 & 09 & 3,6 & {$[1,6$ a 6,7$]$} \\
\hline $\begin{array}{l}\text { 4-Central Mineira/Oeste de } \\
\text { Minas/Metropolitana de Belo Horizonte }\end{array}$ & 293 & 04 & 1,4 & {$[0,37$ a 3,4$]$} \\
\hline 5-Sul/Sudoeste de Minas & 278 & 10 & 3,6 & {$[1,7$ a 6,5$]$} \\
\hline 6-Triângulo Mineiro/Alto Paranaíba & 232 & 04 & 1,7 & {$[0,47$ a 4,3$]$} \\
\hline 7-Campo das Vertentes/Zona da Mata & 290 & 06 & 2,1 & {$[0,76$ a 4,4$]$} \\
\hline Minas Gerais & 1.940 & 115 & 5,3 & {$[4,3$ a 6,3$]$} \\
\hline
\end{tabular}

À semelhança dos resultados encontrados para prevalência de rebanho, as maiores prevalências de eqüídeos de serviço positivos para AIE foram encontradas nos estratos 1-Norte/Noroeste de Minas $(7,4 \%)$ e 2-Vale do Mucuri/Jequitinhonha $(4,8 \%)$ e a menor foi a do estrato 4-Central Mineira/Oeste de Minas/Metropolitana de Belo Horizonte $(0,38 \%)$ (Tab. 5). Esses resultados reforçam os dados anteriores de que as regiões representadas neste estudo pelos estratos 1 e 2 apresentaram alta prevalência, enquanto as demais se situaram em níveis de prevalência de AIE, significativamente menores.

A prevalência geral de animais de serviço, em Minas Gerais, foi estimada em 3,1\%, IC (95\%) = [2,2 a $3,9 \%]$. 
Tabela 5. Prevalência da AIE em eqüídeos de serviço (positivos ao IDGA) em Minas Gerais

\begin{tabular}{|c|c|c|c|c|}
\hline \multirow{2}{*}{ Estrato } & \multicolumn{2}{|c|}{ Total de eqüídeos } & \multirow{2}{*}{$\begin{array}{c}\text { Prevalência } \\
(\%)\end{array}$} & \multirow{2}{*}{$\begin{array}{c}\begin{array}{c}\text { Intervalo de } \\
\text { confiança }(95 \%)\end{array} \\
(\%)\end{array}$} \\
\hline & Amostrados & Positivos & & \\
\hline 1-Norte/Noroeste de Minas & 1.077 & 77 & 7,4 & {$[4,4$ a 10,3$]$} \\
\hline 2-Vale do Mucuri/Jequitinhonha & 1.436 & 62 & 4,8 & {$[2,8$ a 6,8$]$} \\
\hline 3-Vale do Rio Doce & 917 & 09 & 0,92 & {$[0,32$ a 1,5$]$} \\
\hline $\begin{array}{l}\text { 4-Central Mineira/Oeste de } \\
\text { Minas/Metropolitana de Belo Horizonte }\end{array}$ & 914 & 04 & 0,38 & {$[0,0$ a 0,76$]$} \\
\hline 5-Sul/Sudoeste de Minas & 786 & 10 & 1,1 & {$[0,41$ a 1,8$]$} \\
\hline 6-Triângulo Mineiro/Alto Paranaíba & 706 & 04 & 0,52 & {$[0,0$ a 1,0$]$} \\
\hline 7-Campo das Vertentes/Zona da Mata & 704 & 06 & 0,73 & {$[0,14$ a 1,3$]$} \\
\hline Minas Gerais & 6.540 & 172 & 3,1 & {$[2,2$ a 3,9$]$} \\
\hline
\end{tabular}

Os estratos 1 e 2 , nos quais foram verificadas as mais altas prevalências, são regiões onde predominam grandes propriedades, com estradas em péssimas condições, especialmente nas épocas de chuva, com criação extensiva de gado de corte, cujo trato diário depende da utilização dos eqüídeos, sendo que, em determinadas áreas, esses constituem a única opção de transporte. Tais observações, aliadas ao fato de a enfermidade ser caracterizada por um grande percentual de portadores assintomáticos (Issel e Coggins, 1979; Sellon, 1993), induzem os proprietários a não participarem das ações de combate à doença, prescritas em lei, principalmente em relação ao sacrifício imediato dos portadores e à interdição, do trânsito de eqüídeos nas fazendas, até o completo saneamento do foco. Dessa forma, a doença mantem-se no campo. Tais dificuldades já foram relatadas em vários países das Américas (Simpósio..., 1982; Campbell e Nusbaum, 1991). Santos et al. (2001), durante estudos conduzidos no estado do Acre, também encontraram as maiores freqüências de AIE em regiões distantes da capital e com estradas em péssimas condições, onde é difícil o acesso ao diagnóstico laboratorial e à assistência veterinária.

Segundo o CRMV-MG ${ }^{3}$, somente $8 \%$ dos 5.336 profissionais nele inscritos atuavam nos estratos 1 e 2. Tal fato pode estar também contribuindo para a alta prevalência encontrada nessas regiões, pois a deficiência de assistência veterinária dificulta o acesso dos proprietários e dos responsáveis pelas fazendas a informações de ordem sanitária, que poderiam ajudar na prevenção da AIE. Outros fatores que

\footnotetext{
${ }^{3}$ Conselho Regional de Medicina Veterinária (CRMV-MG) - Belo Horizonte, MG.
}

provavelmente influem na prevalência da enfermidade nesses estratos são o clima e outras condições ambientais favoráveis, para o desenvolvimento de vetores.

A maioria dos criatórios especializados em eqüídeos de raça, segundo informações obtidas em associações de criadores ${ }^{4}$, situa-se nos estratos onde a prevalência da AIE foi de média de baixa. Nesses criatórios, há a preocupação em sacrificar o mais rápido possível os animais portadores, quando identificados, e em promover o saneamento da propriedade. É de se esperar que, nessas regiões, a identificação dos animais de serviço positivos, acompanhada de pressão dos criadores de eqüídeos no sentido de sacrificar, rapidamente, o animal e promover o saneamento do foco. Ainda, segundo o CRMVMG, a grande maioria dos veterinários atuantes estava distribuída nessas áreas, sendo que, no estrato 4, cuja prevalência da AIE foi a menor, concentravam-se $43 \%$ dos profissionais.

Bevilacqua et al. (1996) analisaram 66.533 resultados de exames de IDGA, (dados secundários, amostragem não probabilística e que contemplou rebanhos de raça e de serviço), no período de 1973 a 1991 e estimaram prevalência de período de $8,7 \%$ para a mesorregião Noroeste Mineiro e de 6,6\% para a mesorregião Nordeste Mineiro. A prevalência geral de eqüídeos positivos para a AIE foi de $4,1 \%$, resultados que se assemelham aos obtidos neste estudo, o que indica que as ações adotadas

\footnotetext{
4 Associação Brasileira dos Criadores de Cavalos das Raças Mangalarga Marchador (BH/MG), Campolina (BH/MG), Pampa (BH/MG), Pêga (BH/MG), Pônei (BH/MG) e Appaloosa (SP/SP)
} 
para o controle da AIE não estão contribuindo para a diminuição da sua prevalência no estado.

Os resultados obtidos permitem direcionar e priorizar o plano de controle da enfermidade no estado, ajustando-o à epidemiologia da doença e à realidade sócio-econômica regional. Adicionalmente, é importante implantar um programa de educação sanitária específico para o público que lida no dia-a-dia com os eqüídeos no estado, universalizar o acesso dos proprietários de eqüídeos ao exame de diagnóstico oficial, aprovar o ELISA, como teste de triagem para saneamento de propriedades e levantamentos oficiais. Em relação à atuação nos focos de AIE para os estratos 1 e 2, referente ao sacrifício imediato dos positivos como única opção, deveria ser criado um fundo de indenização, com participação da iniciativa privada, para proprietários, sobretudo carentes. Além disso, realizar estudos sobre a ecologia dos vetores, visando identificar quais as espécies de tabanídeos presentes no estado, determinar sua sazonalidade e a abundância nos diferentes habitats.

\section{CONCLUSÕES}

A AIE é uma enfermidade endêmica em Minas Gerais, que apresenta duas áreas epidemiologicamente distintas, sendo uma de prevalência alta ao norte, e outra, ao sul da primeira, com prevalência significativamente mais baixa.

\section{AGRADECIMENTOS}

À Professora Erna Geessien Kroon pelo fornecimento do antígeno rgp90 e ao Instituto Mineiro de Agropecuária (IMA) pelo apoio técnico.

\section{REFERÊNCIAS BIBLIOGRÁFICAS}

BANCO de dados agregados. IBGE, 2001. Disponível em:

$<$ http:sidra.ibge.gov.Br/bda/tabela/protabl.asp? $\mathrm{z}=\mathrm{t} \& \mathrm{o}$ $=12>$ Acessado em 02/11/2003.

BEVILACQUA, P.D; MODENA, C.M.; MOREIRA, E.C. et al. Definição dos ecossistemas para anemia infecciosa eqüina em Minas Gerais, Brasil, 1973-1991. Arq. Bras. Med. Vet. Zootec., v.48, p.7-18, 1996.

BRASIL. Resolução número 4/2004. Controle da anemia infecciosa eqüina no estado de Minas Gerais. Diário Oficial da União, n.138, seção 1, p.92, 2004.

CAMPBELL, C.T.; NUSBAUM, S.R. Epidemiologic importance of interstate transport of equids infected with equine infectious anemia vírus. J. Am. Vet. Med. Assoc., v. 198, p. 1332-1333, 1991.

CLABOUGH, D.L. The immunopathogenesis and control of equine infectious anemia. Vet. Med., v.85, p.1020-1027, 1990 .

COCHRAN, W.G. Sampling techniques. 3. ed. New York: John Wiley \& Sons, 1977. 428p.

COGGINS, L.; NORCROSS, N.L. Immuno-diffusion reaction in equine infectious anemia. Cornell Vet., v.60, p.330-335, 1970.

COGGINS, L.; NORCROSS, N.L.; NUSBAUM, S.R. Diagnosis of equine infectious anemia by immunodiffusion test. Am. J. Vet. Res., v.33, p11-18, 1972.

COOK, S.J.; COOK, R.F.; MONTELARO, R.C. et al. Differencial responses of Equus caballus and Equus asinus to infection with two pathogenic strains of equine infectious anemia virus. Vet Microbiol., v.79, p.93-109, 2001.

DEAN, A.G. EpiInfo version 6: a word-processing, database, and statistic program for public health on IBM-compatible microcomputers. Atlanta: Center for Diseases Control and Prevention, 1994. 601 p.

DONALD, A.W.; GARDNER, I.A. Cutt-off points for aggregate herd testing in the presence of disease clustering and correlation of test erros. Prev. Vet. Med., v.19, p.167-187, 1994.

EPIINFO 6.04d. Atlanta: Center for disease control and prevention, 2001. Disponível em: $<$ http://www.cdc.gov>. Acessado em 10 de fev. 2004.

GANADERIA y produtos pecuários. Bol. FAO, v.3, p.85-87, 2002.

HERDACC version 3. Guelph: University of Guelph, 1995. Disponível em <http://www.etscchools.co.uk /EpiVetNet/files/herdacc.exe $>$. Acessado em: $10 \mathrm{de}$ set 2003.

ISSEL, C.J.; COGGINS, L. Equine infectious anemia: current knowledge. J. Am. Vet. Med. Assoc., v.174, p.727-733, 1979.

JORDAN, D. Aggregate testing for evaluation of Johne's disease herd status. Aust. Vet. J., v.73, p.1619, 1996.

MARTIN, S.W.; SHOUKRI, M.; THORBURN, M. A. Evaluating the health status of herds based on tests 
applied to individuals. Prev. Vet. Med., v.14, p.33-43, 1992.

MARTINS, M. F. Comparação entre os testes IDGA (p26) e ELISA indireto (rgp90) no diagnóstico da anemia infecciosa eqüina. 2004. 59f. Dissertação (Mestrado em Medicina Veterinária) - Escola de Veterinária, Universidade Federal de Minas Gerais, Belo Horizonte.

MONTELARO, R.C.; WEST, M.; ISSEL, C.J. Antigenic reactivity of the mayor glycoprotein of equine infectious anemia virus, a retrovirus. Virology, v.136, p.368-374, 1984.

NOORDHUIZEN, J.P.T.M.; FRANKENA, K.; VAN DER HOOFD, C.M. et al. Application of quantitative methods in veterinary epidemiology. Wageningen: Wageningen, 1997. 445p.

REIS, J.K.P. Produção de antígenos recombinantes gp90 e p26 do vírus da anemia infecciosa eqüina, para uso em imunodiagnóstico. 1997. 184f. Dissertação (Doutorado em Medicina Veterinária) Escola de Veterinária, Universidade Federal de Minas Gerais, Belo Horizonte.

REIS, J.K.P.; MELO, L.M.; REZENDE, M.R. et al. Use of an ELISA test in the eradication of an equine infectious anaemia focus. Trop. Anim. Health. Prod., v.26, p.65-68, 1994.
SANTOS, R.M.L.; REIS, J.K.P.; SANTOS, F. G. A. et al. Freqüência de anemia infecciosa em eqüinos no Acre, 1986 a 1996. Arq. Bras. Med. Vet. Zootec., v.3, p.310-315, 2001.

SELLON, D.C. Equine infectious anemia. Vet. Clin. N. Am.: Equine Pract.. v.9, p.321-336, 1993.

SHANE, B.S.; ISSEL, C.J.; MONTELARO, R.C. Enzyme linked immunosorbent assay for detection of equine infectious anemia virus p26 antigen and antibody. J. Clin. Microbiol., v.19, p.351-355, 1984.

SHEN, D.T.; GORHAM, J.R.; MC GUIRE, T.C. Enzyme linked immunosorbent assay for detection of equine infectious anemia antibody to purified p26 viral protein. Am. J. Vet. Res., v.45, p.1542-1543, 1984.

SIMPÓSIO INTERNACIONAL DE ANEMIA INFECCIOSA EQÜINA, 2., 1982, São Paulo. Anais... São Paulo: Instituto Biológico de São Paulo, 1982.

SUGIURA, T.; MATSUMURA, T.; FUKUNAGA, Y. Diagnosis of equine infectious anemia by enzymelinked immunosorbent assay with viral antigen purified by affinity chromatography. Bull. Equine Res. Inst., n. 23, p. 42-48, 1986.

THRUSFIELD, M. Veterinary epidemiology. 2.ed. Cambridge: Blackwell Science, 1995. 479 p. 